treatment. Statistical analysis: The radiographic progression has been evaluated in both the completers and after Linear Extrapolation (LE) and Last Observation Carried Forward (LOCF) technique in case of missing data. The predictive factors of radiographic progression were evaluated on the completer population using multilevel binomial GEE analysis incorporating measurements from all readers at 5-years and taking into account the within-reader correlation.Moreover, the progression rate was assessed in subgroups of patients according to CRP status and MRI-SIJ status at baseline.

Results: At baseline, 62 out of the 416 patients (14.9\%) were considered r-ax-SpA. Out of these 416 patients, $24(5.8 \%)$ changed from mNY negative to $\mathrm{mNY}$ positive after 5 -years. Conversely, 3 patients changed from $\mathrm{mNY}$ positive at baseline to negative at year 5 (e.g. $0.7 \%$ ) resulting in a net progression of $5.1 \%$. These results were similar when applying LOCF and LE $(4.1 \%$ and $3.8 \%$ net progression)

In the multivariate analysis, presence of BME at MRI-SIJ was highly predictive of radiographic progression ( $\mathrm{OR}=4.85$ [95\% $\mathrm{Cl}: 2.95-7.97])$ together with a younger age (OR=0.97 [95\% Cl: $0.94-0.99])$ and longer symptom duration ( $\mathrm{OR}=1.40[95 \%$ Cl: 1.04-1.89]).

Of the 383 patients with complete data, the net \% patients who switched from nr-axSpA to r-axSpA after 5 years ranged from $2.0 \%$ to $13.5 \%$ according to the presence of objective signs of inflammation at baseline (see figure).

Fig: Net \% patients who switched from nr to r-axSpA after 5 years of follow-up

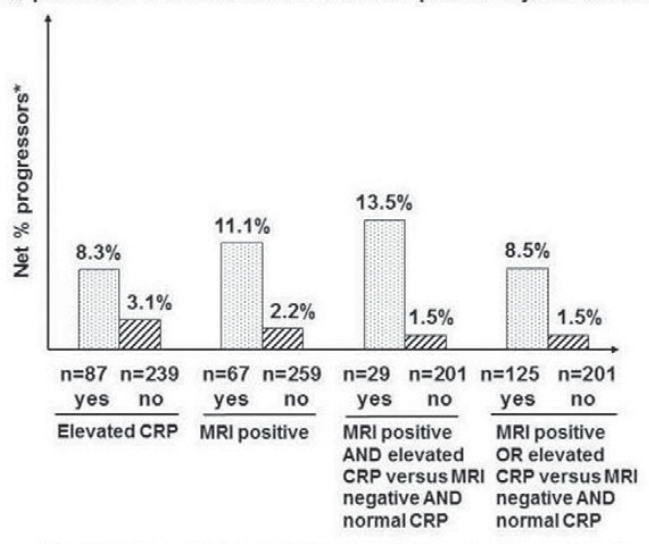

* $\%$ patients who switched from nr to r-axSpA minus $\%$ patients who switched from r to nr-axSpA according to the $\mathrm{mNY}$ criteria

Conclusions: This is the first cohort in early axSpA with 5-year follow-up demonstrating the importance of presence of objective signs of inflammation as predisposing factors of development of radiographic sacroiliitis.

Disclosure of Interest: None declared

DOI: 10.1136/annrheumdis-2017-eular.1637

\section{OP0117 BONE MARROW OEDEMA IN SACROILIAC JOINTS OF YOUNG ATHLETES SHOWS MOST FREQUENTLY IN THE POSTERIOR INFERIOR ILIUM}

U. Weber ${ }^{1}$, A.G. Jurik ${ }^{2}$, A. Zejden ${ }^{2}$, E. Larsen ${ }^{3}$, S.H. Jørgensen ${ }^{3}$, K. Rufibach ${ }^{4}$, C. Schioldan ${ }^{3}$, S. Schmidt-Olsen ${ }^{3}{ }^{1}$ University of Southern Denmark, Odense; ${ }^{2}$ Aarhus University, Aarhus; ${ }^{3}$ North Denmark Regional Hospital, Hjørring, Denmark; ${ }^{4}$ F. Hoffmann-La Roche, Basel, Switzerland

Background: Low grade bone marrow oedema (BMO) was reported in the sacroiliac joints (SIJ) of up to $25 \%$ of healthy individuals and mechanical back pain patients, challenging the imaging discrimination from early spondyloarthritis (SpA) [1]. Potential explanations range from mechanical stress lesions to vascular signals and anatomical SIJ variants.

Objectives: To determine BMO frequency and anatomical distribution in $8 \mathrm{SIJ}$ regions in hobby and professional athletes.

Methods: The sample consisted of 2 cohorts of 20 healthy hobby runners (HR) before and after running and 22 professional ice hockey players (IP) from the Danish premier league: HR/IP 40\%/100\% men; mean age (SD) $27.2(5.4) / 25.9$ (4.6) years; mean BMI (SD) $22.6(1.5) / 25.7(1.6) \mathrm{kg} / \mathrm{m}^{2}$. Semicoronal MRI scans of the SIJ with T1SE and STIR sequences were obtained in HR before and 24 hours after a running competition over 6.2 kilometers (mean duration 35.4 minutes, mean speed $10.4 \mathrm{~km} / \mathrm{h}$ ), and in IP during the competitive season. The scans were assessed for BMO independently by 3 blinded readers (AGJ, AZ, UW) according to the quadrant based MORPHO module (www.carearthritis.com). Paired images of HR were read blinded to timepoint. $7 \mathrm{MRI}$ scans (2 paired images) of SpA patients under TNF treatment served to mask readers. A pre-test reader calibration used MRI scans from 11 patients with active sacroilitis and 9 healthy volunteers. Reader agreement was assessed by ICC $(3,1)$. Descriptive analysis comprised mean frequency of SIJ quadrants with BMO and distribution of BMO quadrants in 8 anatomical SIJ regions: upper/lower ilium and sacrum, subdivided in anterior and posterior slices, as concordantly recorded by the majority $(\geq 2 / 3)$ of readers.
Results: Agreement among 3 readers for SIJ BMO was excellent in calibration (ICC 0.93) and moderate in athletes (ICC 0.59) due to low frequency of BMO. The mean number (SD) of SIJ quadrants showing BMO was 3.1 (4.2)/3.1 (4.5) in HR before/after running, and 3.6 (3.0) in IP. The posterior inferior ilium was the single most affected region, followed by the upper anterior sacrum, consistently across 2 cohorts of athletes.

Table 1. Frequency and anatomical distribution of SIJ quadrants with BMO in 2 cohorts of athletes

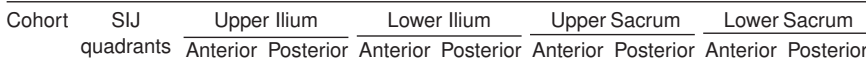

HR before

Mean (SD) 0.1 (0.4) 0.1 (0.3) $0.2(0.7) \quad 1.4$ (1.9) 0.5 (0.9) 0.1 (0.4) $0.3(0.6) 0.5(1.6)$ $\begin{array}{lllllllll}\geq 1 \mathrm{Q}(\mathrm{n}) & 3 & 0 & 1 & 8 & 4 & 2 & 3 & 1 \\ \geq 2 & 0 & 0 & 0 & 0\end{array}$ $\begin{array}{lllllllll}\geq 2 Q(n) & 0 & 0 & 1 & 6 & 3 & 0 & 0 & 1 \\ \geq 3 Q(n) & 0 & 0 & 1 & 2 & 1 & 0 & 0 & 1\end{array}$

HR after

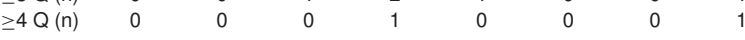

Mean (SD) $0.2(0.4) \quad 0(0.1) \quad 0.3(0.8) \quad 1.2(1.7) \quad 0.5(1.0) \quad 0.2(0.7) \quad 0.3(0.7) \quad 0.5(1.6)$ $\begin{array}{lllllllll}\geq 1 \mathrm{Q}(\mathrm{n}) & 2 & 0 & 2 & 9 & 3 & 2 & 3 & 1 \\ \geq 2 \mathrm{Q}(\mathrm{n}) & 0 & 0 & 1 & 6 & 2 & 1 & 0 & 1\end{array}$ $\geq 3 Q(n)$ $4 Q$ (n) -0.0

IP $\quad \begin{array}{ccccccccc}\geq 4 Q(n) & 0 & 0 & 1 & 1 & 0 & 0 & 0 & 1 \\ \quad \text { Mean (SD) } & 0.1(0.4) & 0.1(0.3) & 0.5(0.8) & 1.9(1.9) & 0.6(1.1) & 0.1(0.4) & 0.2(0.6) & 0.1(0.6)\end{array}$ $\begin{array}{lllllllll}\geq 1 \mathrm{Q}(\mathrm{n}) & 0 & 1 & 7 & 13 & 3 & 0 & 3 & 0 \\ \geq 2 \mathrm{Q}(\mathrm{n}) & 0 & 0 & 4 & 11 & 2 & 0 & 1 & 0\end{array}$

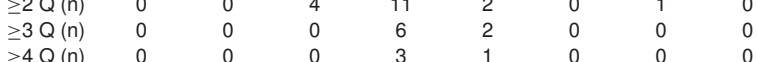

Abbreviations. Q: SIJ quadrants with BMO. $\geq 1 / 2 / 3 / 4 Q$ (n): number of subjects $(n)$ with $\geq 2 / 3$ readers indicating $\geq 1 / 2 / 3 / 4$ SIJ quadrants with $B M O$.

Conclusions: In hobby and professional athletes, BMO showed on average in 3-4 SIJ quadrants. The posterior lower ilium was the SIJ region most frequently affected by BMO. These findings in healthy controls may help refine thresholds for a positive SIJ MRI in early SpA.

References:

[1] Weber U et al. Curr Rheumatol Rep 2016;18:58.

Disclosure of Interest: None declared

DOI: 10.1136/annrheumdis-2017-eular.4352

\section{OP0118 IMPACT OF RADIOGRAPHIC DAMAGE IN THE SACROILIAC JOINTS ON FUNCTION AND SPINAL MOBILITY IN PATIENTS WITH AXIAL SPONDYLOARTHRITIS: RESULTS FROM THE GERMAN SPONDYLOARTHRITIS INCEPTION COHORT}

M. Protopopov ${ }^{1}$, J. Sieper ${ }^{1}$, H. Haibel ${ }^{1}$, J. Listing ${ }^{2}$, M. Rudwaleit ${ }^{3}$, D. Poddubnyy ${ }^{1} .{ }^{1}$ Department of Gastroenterology, Infectiology and Rheumatology, Charité Universitätsmedizin Berlin; ${ }^{2}$ German Rheumatism Research Centre, Berlin; ${ }^{3}$ Klinikum Bielefeld Rosenhöhe, Bielefeld, Germany

Background: It has been shown in the past that the spinal mobility in patients with axial spondyloarthritis $(\mathrm{AxSpA})$ is associated with spinal structural damage, disease activity parameters and spinal inflammation [1]. The impact of radiographic damage in the sacroiliac joints on functional parameters in patients with axial spondyloarthritis has not been investigated so far.

Objectives: To analyze the association between radiographic sacroiliitis and parameters of the functional status and spinal mobility in patients with axSpA. Methods: Altogether 210 patients with definite axSpA (115 with radiographic and 95 with non-radiographic axSpA) from the German Spondyloarthritis Inception Cohort (GESPIC) were included in the current study. Radiographs of sacroiliac joints were obtained at baseline and after 2 years of the follow up and were scored by two trained readers according to the conventional grading system of the modified New York criteria (grade 0 to 4 per joint). A mean of two readers score for each joint and a sum score for both SIJ were calculated for each patient, giving a total sacroiliitis score between 0 and 8 . Functional status and spinal mobility were assessed by means of the Bath Ankylosing Spondylitis Functional Index (BASFI) and the Bath Ankylosing Spondylitis Metrology Index (BASMI), respectively. Both baseline and year 2 data were included in the longitudinal mixed models analysis that was corrected for the dependencies between the two time-point values of each individual and adjusted for the structural damage in the spine (modified Stoke Ankylosing Spondylitis Spine Score - mSASSS), disease activity (the Bath Ankylosing Spondylitis Disease Activity Index - BASDAI and level of C-reactive protein - CRP), and sex.

Results: In the longitudinal mixed model analysis adjusted for the presence of structural damage in the spine (mSASSS), disease activity (BASDAI and CRP) and sex, radiographic sacroiliitis demonstrated an independent association with the BASFI: $\beta=0.10(95 \% \mathrm{Cl} 0.01-0.19)$ and the BASMI: $\beta=0.12(95 \% \mathrm{Cl} 0.03-$ 0.21 ), respectively - table. These data indicate that change by one radiographic sacroiliitis grade in one sacroiliac joint is associated with a BASFI/BASMI worsening by $0.10 / 0.12$ points independently of structural damage in the spine and disease activity. Assuming linear association, progression of radiographic sacroiliitis from grade 0 bilaterally to grade 4 bilaterally would result in a worsening by 0.8 points in BASFI and 0.96 points in BASMI. Sensitivity analysis performed in radiographic and non-radiographic axSpA subgroups provided similar results for both outcomes.

Conclusions: Radiographic damage in the sacroiliac joints might have an impact, 
Table. Association between the sum radiographic sacroiliitis score and functional status / spinal mobility in patients with axial spondyloarthritis.

\begin{tabular}{|c|c|c|}
\hline Parameters & $\begin{array}{l}\text { Unadjusted mixed model } \\
\text { analysis } \\
\beta(95 \% \mathrm{Cl})\end{array}$ & $\begin{array}{c}\text { Adjusted mixed model } \\
\text { analysis } \\
\beta(95 \% \mathrm{CI})\end{array}$ \\
\hline \multicolumn{3}{|c|}{ Outcome: BASFI } \\
\hline Sacroiliitis sum score (0-8) & $0.09(-0.05$ to 0.22$)$ & $0.10(0.01$ to 0.19$)$ \\
\hline mSASSS, points (0-72) & - & 0.05 (0.03 to 0.07$)$ \\
\hline BASDAI, points NRS (0-10) & - & 0.81 (0.74 to 0.88$)$ \\
\hline CRP, $\mathrm{mg} / \mathrm{l}$ & - & $0.00(-0.01$ to 0.01$)$ \\
\hline Male vs. Female sex & - & $-0.02(-0.40$ to 0.37$)$ \\
\hline \multicolumn{3}{|c|}{ Outcome: BASMI } \\
\hline Sacroiliitis sum score (0-8) & $0.20(0.11$ to 0.30$)$ & $0.12(0.03$ to 0.21$)$ \\
\hline mSASSS, points (0-72) & - & $0.07(0.05$ to 0.09$)$ \\
\hline BASDAI, points NRS (0-10) & - & $0.22(0.15$ to 0.29$)$ \\
\hline CRP, $\mathrm{mg} / \mathrm{l}$ & - & $0.01(0.00$ to 0.02$)$ \\
\hline Male vs. Female sex & - & $0.00(-0.39$ to 0.39$)$ \\
\hline
\end{tabular}

mSASSS - modified Stoke Ankylosing Spondylitis Spine Score; AS - Ankylosing Spondylitis; nr-axSpA non-radiographic axial spondyloarthritis; BASFI - Bath Ankylosing Spondylitis Functional Index; CRP . C-reactive protein; BASDAI - Bath Ankylosing Spondylitis Disease Activity Index; BASMI - Bath Ankylosing Spondylitis Metrology Index.

although small, on spinal mobility and physical function in patients with axial SpA independently of structural damage in the spine and disease activity.

\section{References:}

[1] Machado P. et al. Ann Rheum Dis 2010; 69:1465-1470.

Acknowledgements: GESPIC has been financially supported by the German Federal Ministry of Education and Research (BMBF). As funding by BMBF was reduced in 2005 and stopped in 2007, complementary financial support has been obtained also from Abbott/Abbvie, Amgen, Centocor, Schering-Plough, and Wyeth. Since 2010 GESPIC is supported by Abbvie.

Disclosure of Interest: None declared

DOI: 10.1136/annrheumdis-2017-eular.3453

\section{OP0119 EVALUATION OF THE PREDICTIVE VALIDITY OF THE ASAS AXIAL SPONDYLOARTHRITIS CRITERIA IN THE DESIR COHORT}

B. Meghnathi ${ }^{1}$, A. Etcheto ${ }^{1}$, A. Saraux ${ }^{2}$, M. Dougados ${ }^{1}$, A. Moltó ${ }^{1} \cdot{ }^{1}$ Paris Descartes University, Medicine Faculty; APHP, Rheumatology B Department, Cochin Hospital, Paris; ${ }^{2}$ La Cavale Blanche Hospital, Rheumatology and Université Bretagne Occidentale, Brest, France

Background: The face validity ${ }^{1}$ and cross-sectional external validity ${ }^{2}$ of the Assessment of SpondyloArthritis international Society (ASAS) criteria for axial spondyloarthritis (axSpA), and its arms has been already confirmed in previous studies. However, so far, only one study ${ }^{3}$ has reported data regarding the predictive validity of such criteria after 4 years of follow-up.

Objectives: To evaluate the predictive validity of the ASAS criteria and its arms after 5 years of follow-up. The predictive validity of the other axSpA sets of criteria (Amor, ESSG and $\mathrm{mNY}$ ) was also evaluated.

Methods: Patients: This analysis was performed on the DESIR cohort. A total of 708 adult ( $>18$ and $<50$ years) patients presented with inflammatory back pain suggestive of axSpA (according to the rheumatologist's conviction of $\geq 5 / 10$ ) for $>3$ months but $<3$ years duration. They were followed up every 6 months for the first 2 years and then yearly up to 5 years. Starting from month 24, as per protocol, patients could be excluded from the cohort in case another diagnosis (different from $\mathrm{SpA}$ ) was made.

Methods: The gold standard for this analysis was the diagnosis of axSpA according to the rheumatologist at 5 years of follow-up. For this analysis, patients were considered as axSpA, if the rheumatologist at 5 years with a conviction of $\geq 7 / 10$ for an axSpA diagnosis. Conversely, patients excluded as per protocol due to another diagnosis or patients with a rheumatologist conviction at 5 years of $\leq 3 / 10$ for axSpA were considered as Non-axSpA. The set of criteria collected at baseline (ASAS, and its arms, Amor, ESSG and mNY: fulfilled/not fulfilled) were tested against the Rheumatologist's axSpA diagnosis (fulfilled/not fulfilled) after 5 years of follow-up. Predictive validity of all sets of criteria at baseline was evaluated by the positive predictive value (PPV).

Results: In total, among the 708 patients included in the DESIR cohort at baseline, data on Rheumatologists diagnosis at 5 years was available in 454 patients; amongst them, 352 ( $77.5 \%)$ had an axSpA diagnosis according to the rheumatologist. Among these 352 patients, 245, 300, 291 and 88 patients fulfilled the ASAS criteria for axSpA, Amor, ESSG and modified NY criteria's respectively. Figure 1 shows the PPV $(95 \% \mathrm{Cl})$ of the different sets of criteria below.

Conclusions: Predictive validity of the ASAS criteria for axSpA (including both arms) at 5 years was excellent; it is worth noting that the performances of the other criteria were also very good.

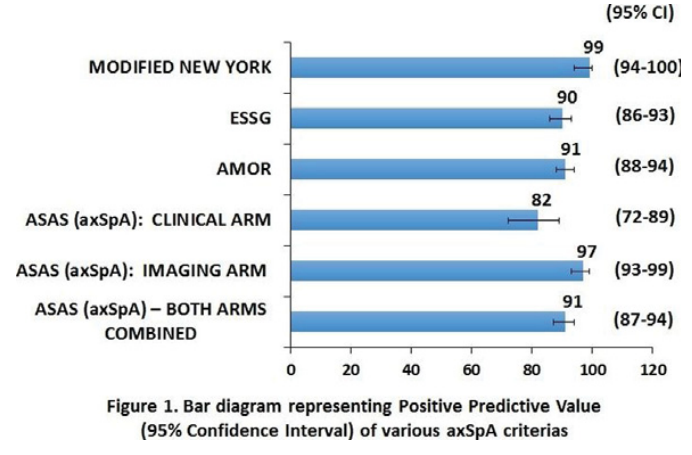

\section{References:}

[1] Molto A et al. Performances of the Assessment of SpondyloArthritis International Society Axial Spondyloarthritis Criteria for Diagnostic and Classification Purposes in Patients Visiting a Rheumatologist Because of Chronic Back Pain: Results From a Multicenter, Cross-Sectional Study. Arthritis Care \& Research 2013;65:1472-81.

[2] Molto A et al. Evaluation of the validity of the different arms of the ASAS set of criteria for axial spondyloarthritis and description of the different imaging abnormalities suggestive of spondyloarthritis: data from the DESIR cohort. Ann Rheum Dis 2015;74:746-51.

[3] Sepriano A et al. Predictive validity of the ASAS classification criteria for axial and peripheral spondyloarthritis after follow-up in the ASAS cohort: a final analysis. Ann Rheum Dis. 2016;75:1034-42.

Acknowledgements: The DESIR cohort is financially supported by unrestricted grants from the French Society of Rheumatology and Pfizer France.

Disclosure of Interest: B. Meghnathi Grant/research support from: ASAS Society (ASAS FELLOW), A. Etcheto: None declared, A. Saraux: None declared, M. Dougados: None declared, A. Moltó: None declared

DOI: 10.1136/annrheumdis-2017-eular.3490

\section{OP0120 THE ROLE OF SMOKING IN THE DEVELOPMENT AND PROGRESSION OF STRUCTURAL DAMAGE IN PATIENTS WITH ANKYLOSING SPONDYLITIS: THE PRELIMINARY RESULTS OF A SYSTEMATIC REVIEW AND META-ANALYSIS}

S. Akar ${ }^{1}$, Y.C. Kaplan ${ }^{2}$, S. Ecemis ${ }^{1}$, E.K. Arslan ${ }^{2}$, O. Gercik ${ }^{1}$, D. Solmaz ${ }^{1}$. ${ }^{1}$ Rheumatology; ${ }^{2}$ Pharmacology, Izmir Katip Celebi University Faculty of Medicine, Izmir, Turkey

Background: Smoking may constitute a major risk factor for not only disease susceptibility but also disease severity in patients with ankylosing spondylitis (AS). Some previous cross-sectional and longitudinal studies suggested that smoking may be associated with cumulative spinal radiographic damage and regarded it as an independent predictor of spinal radiographic progression.

Objectives: The objective of this study is to determine whether smoking is associated with the cumulative radiographic spinal structural damage and radiographic progression in AS patients. In order to reach this objective, we conducted a systematic review and meta-analysis of the available studies to-date. Methods: An electronic search was conducted from inception to June 21 2016 in EMBASE, MEDLINE/PubMed Cochrane Central Register of Controlled Trials databases. Cross-sectional and longitudinal cohort studies investigating the association between smoking and cumulative spinal structural damage or radiographic progression were included. The outcome of interest were the presence of syndesmophytes in cross-sectional studies and radiographic progression in longitudinal studies. Two independent reviewers carried out the screening process. The Quality assessment was done using The Agency for Healthcare Research and Quality (ARHQ) checklist and Newcastle-Ottawa scale. Authors of potential relevant studies were contacted for the unpublished data. Data from eligible cross-sectional studies were extracted and arranged in a $2 \times 2$ table. The odds ratios (ORs) and 95\% confidence intervals (Cls) for the dichotomous outcome of interest were computed. Random-effects method was used to combine the outcome data in Comprehensive Meta Analysis Software Version 3.3.070. Results: The combined data of eight eligible cross-sectional studies for the assessment of association between smoking and cumulative spinal structural damage suggested a significant association (OR, 2.02; 95\% Cl 1.51-2.70) Figure 1. Forest plot of the association between ever-smoking and cumulative spinal structural damege in AS patients

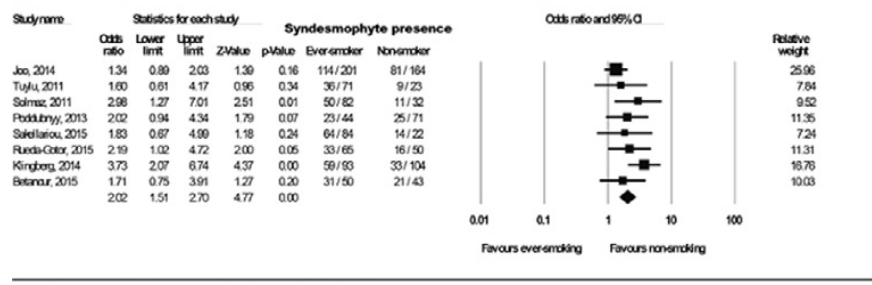

Test of heterogeneity: $Q=9.09$, df $=7(P=0.25), P^{2}=23.0 \%$ 